\title{
Determinants of intimate partner violence during pregnancy among married women in Abay Chomen district, Western Ethiopia: a community based cross sectional study
}

\author{
Bedilu Abebe Abate ${ }^{1 *}$, Bitiya Admassu Wossen² and Tizta Tilahun Degfie ${ }^{3}$
}

\begin{abstract}
Background: Intimate partner violence during pregnancy is the most common form of violence that harms the health of women and the fetus but practiced commonly in developing countries. There is scarcity of information regarding intimate partner violence during pregnancy in Ethiopia. Thus, this study aimed to assess the prevalence and associated factors of intimate partner violence during recent pregnancy in Abay Chomen district, Western Ethiopia.

Methods: Community based cross sectional study was conducted among married pregnant women in Abay Chomen district in April, 2014 using a standard WHO multi-country study questionnaire. Two hundred eighty two randomly selected pregnant women aged 15-49 years participated in the study. Logistic regression and multivariate analysis were employed.

Results: The prevalence of intimate partner violence during recent pregnancy was $44.5 \%$ (95 \% Cl, 32.6, 56.4). More than half 157 (55.5\%) experienced all three forms of intimate partner violence during recent pregnancy. The joint occurrence of intimate partner physical and psychological violence during recent pregnancy as well as joint occurrence of intimate partner physical and sexual violence was 160 (56.5\%). Pregnant women who were ever lived with their partner's family were $46 \%$ less likely to experience recent intimate partner violence. Dowry payment decreases intimate partner violence during recent pregnancy (AOR 0.09, $95 \% \mathrm{Cl} 0.04,0.2$ ) and pregnant women who didn't undergo marriage ceremony during their marriage were $79 \%$ are less likely to experience violence (AOR 0.21,

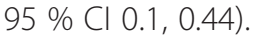

Conclusion: Nearly half of interviewed pregnant women experienced intimate partner violence during pregnancy implying the prevalence of such practice in the study site. To that end, increasing community awareness about the consequences of the practice could be important. Moreover, as health extension workers works closely with households, they could be crucial players to increase community awareness about intimate partner violence on pregnant mothers and halt it or its risk factors.
\end{abstract}

Keywords: Intimate partner violence, Pregnancy, Ethiopia

\footnotetext{
*Correspondence: bediluab@gmail.com

1 Department of Social and Public Health, College of Health Sciences, Debre

Tabor University, Debre Tabor, Ethiopia

Full list of author information is available at the end of the article
} 


\section{Background}

Declaration on the elimination of violence against women defines violence against women as "... any act of genderbased violence that results in, or is likely to result in, physical, sexual or psychological harm or suffering to women, including threats of such acts, coercion or arbitrary deprivation of liberty, whether occurring in public or in private life" [1]. By year 2013, one out of three women experienced violence [2]. Among those violence, intimate partner violence on pregnant women is a global health concern [2]. The WHO multi-country study on women's health and domestic violence against women found the prevalence of physical intimate partner violence as $15 \%$ in Japan to $71 \%$ in Ethiopia and the prevalence of physical domestic violence against women in pregnancy $1 \%$ in Japan city to $28 \%$ in Peru Province, with the majority of sites ranging from 4 to $12 \%$ [3]. Prevalence of violence against pregnant women in developing countries is estimated to be 4 to $29 \%$ [4].

Analysis of demographic and health surveys and the international violence against women survey showed prevalence of intimate partner violence during 'pregnancy to be $2 \%$ in Australia, Denmark, Cambodia and Philippines to $13.5 \%$ in Uganda, with the majority 4 and $9 \%$ [5].

In Ethiopia, community based studies indicated that 50 to $76.5 \%$ of women experienced domestic/intimate partner violence in their life time [6-10]. Prevalence of intimate partner physical violence during pregnancy in rural Ethiopia is reported to be $8 \%$ [3].

Intimate partner violence during pregnancy has been associated with fatal and non-fatal adverse health outcomes for the pregnant woman and her unborn fetus either direct physical trauma to her body and physiological stress from current or past abuse or fetal growth and development [11-15].

Different studies showed that intimate partner violence against pregnant women was significantly associated with adverse maternal health outcomes i.e. unintended pregnancies, pregnancy-related symptom distress, inadequate prenatal care, induced abortion, spontaneous abortion, gestational weight gain, intra uterine restriction, hypertension, pre-eclampsia, third trimester bleeding and STIs. Pregnant women were at higher risk of adverse outcomes including maternal death [16-18].

In low and middle income countries including Ethiopia, there are several gaps and inadequate evidence on prevalence and factors associated with intimate partner violence during pregnancy [4]. Most studies were limited to intimate partner violence to non pregnant women. However, the consequence of intimate partner violence during pregnancy is worse.

Thus, this study assessed magnitude and associated factors of intimate partner violence during pregnancy (IPVDP) in Abay Chomen district, western Ethiopia.

\section{Methods}

\section{Study area}

The study was conducted in Abay Chomen district, Oromia region, western Ethiopia. Abay Chomen district is located in Horro Gudurru Wollega Zone of Oromia region, 246 $\mathrm{Km}$ to the west of Addis Ababa, the capital city of Ethiopia. The district has two administrative towns and 18 rural kebeles, which is the smallest administrative unit in Ethiopia. There were five health centers and 18 health posts in the study area [19].

\section{Study design and population}

Community based cross sectional study was conducted in the district in April, 2014. Study population were randomly selected and pregnant women aged 15-49 years who are living in the study area for at least six months prior to the study were targeted.

Sample size was calculated using a single population proportion formula using the following assumptions; $8 \%$ prevalence of intimate partner violence during pregnancy in rural Ethiopia (3) $95 \%$ confidence level, $3 \%$ margin of error, $10 \%$ allowance for non-response rate. Accordingly, the total sample was 299.

Out of twenty one kebeles of Abay Chomen district, ten kebeles were randomly selected. Updated ANC registration of health extension workers was checked and household pregnant women census was done for one week by six interviewers and numbering was done in the selected kebeles to fix a sampling frame.

A total of 2021 pregnant women who lived at least six months prior to the study period were enumerated. Finally, population proportion allocation was done to identify respondents from the selected households as a study unit. In situations where households had two or more eligible subjects, only one was selected by lottery method.

\section{Data collection method and tools}

Data was collected by six high school completed female interviewers using standard WHO multi-country study of VAW questionnaire [20]. The questionnaire was translated to local language Afan Oromo by experts in both languages and was translated back to English by another person to ensure consistency and accuracy. The data collection process was closely supervised by two health officers and the principal investigator. The data collectors and supervisors were recruited based on previous experience on data collection and fluency in the local language. In addition, training was given for two consecutive days on how to interview, handling ethical issues and maintaining confidentiality and privacy. Pre-test study covered 15 pregnant women in a separate kebele, which become out of the main study.

Pre-test was conducted to familiarize enumerators with the administration of interview process and for ensuring 
consistency. Debriefing sessions were held with the pre test field staff and the questionnaires were modified based on lessons drawn from the pre -test.

\section{Data analysis}

Data was first checked manually for completeness and then coded and entered in to Epi data version 3.5.1. Then the data was exported to SPSS version 16.00 for data checking, cleaning and logistic regression. Cleaning was done by calculating frequencies and sorting. Bivariate analysis between dependent and independent variables was performed using binary logistic regression. $P<0.25$ was used as criteria to select candidate variables for multivariate analysis. Multivariable logistic regression analysis was done to adjust for possible confounding variables. $P$-value $<0.05$ with $95 \%$ confidence interval (CI) for OR (odds ratio) was used in judging the significance of the associations. Results were presented in text, tables and charts.

\section{Ethical considerations}

Ethical approval was obtained from Ethical Review committee of Jimma University. Letter of permission was obtained from Abay Chomen district administration and health offices. The purpose of the study was explained to the study participants and written consent was secured before data collection was started and confidentiality of the information was ensured by coding. For study participants aged less than 18 , we received written informed consent from the participants themselves because they were married and mature minor. The consent procedure was approved by the ethics committee for all including those aged less than 18 years [21]. The interview with the pregnant women was undertaken privately in separate area within the household compound and fieldworkers were trained to refer women requesting assistance to available sources of support according to WHO Ethical and safety recommendation [22]. However, no pregnant women requested support.

\section{Result}

Socio demographic characteristics of pregnant women

A total of 282 out of 299 study subjects were interviewed making a response rate of $94.3 \%$. Majority 135 (47.7\%) of respondents were in the age range of 25-34 years. The mean age of the respondents' was 27 years $( \pm 6.1 \mathrm{SD})$. About two thirds of the respondents' wealth quantile was medium. Nearly half 145 (51.8 \%) of the respondents had no formal education. About two thirds $184(65.0 \%)$ were housewives, and half 143 (50.5\%) of them were grew up in the same community as they born or nearby community/ Kebele (Table 1).

About half (52.3 \%) reported that they had seen women being battered in their childhood and 32 (11.4\%) of them reported that they support pregnant women to be battered by her intimate partner. More than eight in ten 242
Table 1 Socio demographic characteristics of currently married pregnant women, Abay Chomen District, Western Ethiopia, April $2014(n=282)$

\begin{tabular}{|c|c|c|}
\hline Variable & & Number (\%) \\
\hline \multirow[t]{3}{*}{ Age (years) } & $15-24$ & $112(39.6)$ \\
\hline & $25-34$ & $135(47.7)$ \\
\hline & $35-44$ & $36(12.7)$ \\
\hline \multirow[t]{3}{*}{ Religion } & Protestant & $192(67.8)$ \\
\hline & Orthodox & $82(29.0)$ \\
\hline & Others $^{a}$ & $8(2.9)$ \\
\hline \multirow[t]{3}{*}{ Ethnicity } & Oromo & $232(82.0)$ \\
\hline & Amhara & $43(15.2)$ \\
\hline & Others $^{b}$ & $7(2.5)$ \\
\hline \multirow[t]{3}{*}{ Wealth Quintile } & Poor & $79(28.0)$ \\
\hline & Medium & $185(65.6)$ \\
\hline & Rich & $18(6.4)$ \\
\hline \multirow{4}{*}{$\begin{array}{l}\text { Growth areas (refers to where } \\
\text { the mother grows before } \\
12 \text { years of age) }\end{array}$} & The same community & $143(50.5)$ \\
\hline & Other Kebele & $66(23.3)$ \\
\hline & Other town & $40(14.1)$ \\
\hline & Others ${ }^{c}$ & $33(11.6)$ \\
\hline \multirow[t]{4}{*}{ Occupation } & House wife & $184(65.0)$ \\
\hline & Daily laborer & $39(13.8)$ \\
\hline & Private employee & $19(6.7)$ \\
\hline & Gov employee & $25(8.8)$ \\
\hline \multirow[t]{4}{*}{ Education status } & Illiterate & $145(51.6)$ \\
\hline & Elementary & $83(29.5)$ \\
\hline & High school & $43(15.3)$ \\
\hline & Higher education graduate & $10(3.6)$ \\
\hline \multirow[t]{2}{*}{ Live with husband family } & Yes & $137(48.4)$ \\
\hline & No & $145(51.2)$ \\
\hline \multirow[t]{2}{*}{ Live with her family } & Yes & $233(82.3)$ \\
\hline & No & $46(16.3)$ \\
\hline
\end{tabular}

${ }^{a}$ Muslim, Wakefeta

'Tigre, Sidama, and Kembata

'Don't remember/don't know, other neighbor town, refused to answer

$(85.5 \%)$ had a person to whom they might talk when they encounter problem. Forty eight $(17.0 \%)$ were advised by the person to whom they talk to take violence as it is normal, where as $6(2.1)$ and $4(1.1 \%)$ were advised to go to elders and to ask for divorce respectively.

Nearly nine out of ten 50 (88.3\%) of respondents marriage had dowry payment, which they consider has positive impact on how they are treated by their husband and his family and $226(80.1 \%)$ of them reported that the entire dowry was paid. Majority 205 (73.7 \%) of them reported that dowry payment had positive impact on their rest of life. One in three 98 (34.6\%) of the conflict between the husband and the pregnant women was solved by the elders. 
Socio demographic characteristics of the current partner Majority of respondents' partners were between the age of 25-34 157 (55.5\%). About four in ten 106 $(37.5 \%)$ of partners had no formal education. Regarding occupation, 31.8 and $29.3 \%$ of partners were government employees and farmers respectively. More than one in ten $37(13.1 \%)$ of them had other wife and $21(7.4 \%)$ had child from other wife. Nearly nine out of ten partners 251 (88.7\%) provided money for their wives. Nearly half $152(48.1 \%)$ of them drunk alcohol and one in three 88 (31.1\%) drunk 1-2 times a week and more (Table 2).

\section{Reproductive characteristics of pregnant women}

One hundred forty two (50.2\%) of the respondents married in the age between 20-24 years with the mean age of first marriage 19.6 years $( \pm 2.9 \mathrm{SD})$. Nineteen $(42.4 \%)$ of the couples the initiation of marriage was not based on their own choices and one in five 58 (20.5\%) were not volunteer to marry their current partner. Similarly,

Table 2 Socio demographic characteristics of intimate Partner as reported by women, Abay Chomen District, Western Ethiopia, April $2014(n=282)$

\begin{tabular}{|c|c|c|}
\hline Variable & & Number (\%) \\
\hline \multirow[t]{4}{*}{ Age (years) } & $18-24$ & $25(8.8)$ \\
\hline & $25-34$ & $157(55.5)$ \\
\hline & $35-49$ & 79 (27.9) \\
\hline & $>50$ & $22(7.8)$ \\
\hline \multirow[t]{4}{*}{ Education } & Illiterate & $106(37.4)$ \\
\hline & Elementary & $68(24.0)$ \\
\hline & High school & $71(25.1)$ \\
\hline & Higher education graduate & $37(13.1)$ \\
\hline \multirow[t]{6}{*}{ Occupation } & Farmer & $83(29.3)$ \\
\hline & Gov. employee & $90(31.8)$ \\
\hline & Daily laborer & $28(9.9)$ \\
\hline & Merchant & $20(7.1)$ \\
\hline & Priv. employee & $13(4.6)$ \\
\hline & Others $^{\mathrm{a}}$ & $12(4.2)$ \\
\hline \multirow[t]{2}{*}{ Had other wife } & Yes & $37(13.1)$ \\
\hline & No & $244(86.2)$ \\
\hline \multirow[t]{4}{*}{ Alcohol frequency } & Always & $20(7.1)$ \\
\hline & 1-2 times a week & $68(24.0)$ \\
\hline & $1-3$ times a month & $25(8.8)$ \\
\hline & Not drunk & $147(51.9)$ \\
\hline \multirow[t]{2}{*}{ Ever fight with others } & Yes & $55(19.4)$ \\
\hline & No & $223(78.8)$ \\
\hline \multirow[t]{2}{*}{ Had other child } & Yes & $21(7.4)$ \\
\hline & No & $259(91.5)$ \\
\hline
\end{tabular}

${ }^{\mathrm{a} E v a n g e l i s t, ~ R e t i r e d, ~ S t u d e n t ~}$
95 (33.8 \%) of them had never conducted marriage ceremony. Thirty seven $(13.1 \%)$ of them married to partners who had other wife. The mean age at first sex was 17.9 years $( \pm 2.35 \mathrm{SD})$ (Table 3$)$.

\section{Prevalence of violence and its forms}

Intimate partner violence during recent pregnancy was $44.5 \%$. More than half 157 (55.5\%) women experienced all the three forms of intimate partner violence during recent pregnancy. The simultaneous occurrence of intimate partner physical and psychological violence during pregnancy as well as joint occurrence of intimate partner physical and sexual violence was 160 (56.5 \%) (Fig. 1).

Table 3 Reproductive characteristics of currently married pregnant women aged 15-49, Abay Chomen District, western Ethiopia, April $2014(n=282)$

\begin{tabular}{|c|c|c|}
\hline Variable & & Number (\%) \\
\hline \multirow[t]{3}{*}{ Gravida } & One & $106(37.5)$ \\
\hline & Two & $88(31.1)$ \\
\hline & $>=$ Three & $59(31.5)$ \\
\hline \multirow[t]{3}{*}{ Marriage sequence } & First & $252(89.4)$ \\
\hline & Second & $22(7.8)$ \\
\hline & Third and fourth & $8(2.9)$ \\
\hline \multirow[t]{4}{*}{ Marriage Ceremony } & Religious & $58(20.6)$ \\
\hline & Customary marriage & $47(16.7)$ \\
\hline & Civil marriage & $82(29.1)$ \\
\hline & No marriage ceremony & $95(33.7)$ \\
\hline \multirow[t]{5}{*}{ Who choose her husband } & Both & $150(53.0)$ \\
\hline & Husband & $82(29.0)$ \\
\hline & His family & $18(6.4)$ \\
\hline & My family & $17(6.0)$ \\
\hline & I myself & $13(4.6)$ \\
\hline \multirow[t]{2}{*}{ Voluntariness to marry him } & Yes & $220(77.7)$ \\
\hline & No & $58(20.5)$ \\
\hline \multirow[t]{4}{*}{ Dowry /Bride payment } & Yes & $250(88.3)$ \\
\hline & No & $5(1.8)$ \\
\hline & Don't know & $17(6.0)$ \\
\hline & Refused & $10(3.5)$ \\
\hline \multirow[t]{4}{*}{ Dowry/bride } & All paid & $226(79.9)$ \\
\hline & Partially paid & $24(8.5)$ \\
\hline & Don't know & $21(7.4)$ \\
\hline & Refused & $10(3.5)$ \\
\hline \multirow[t]{3}{*}{ Dowry Impact } & Positive impact & $206(73.8)$ \\
\hline & Negative impact & $3(1.1)$ \\
\hline & Nothing & $45(16.1)$ \\
\hline
\end{tabular}

NB: Dowry/bride: refers to dowry/bride price payment to the bride's family in country with this culture like Ethiopia

Dowry impact: refers to on how the pregnant women are treated by their husband and his family 


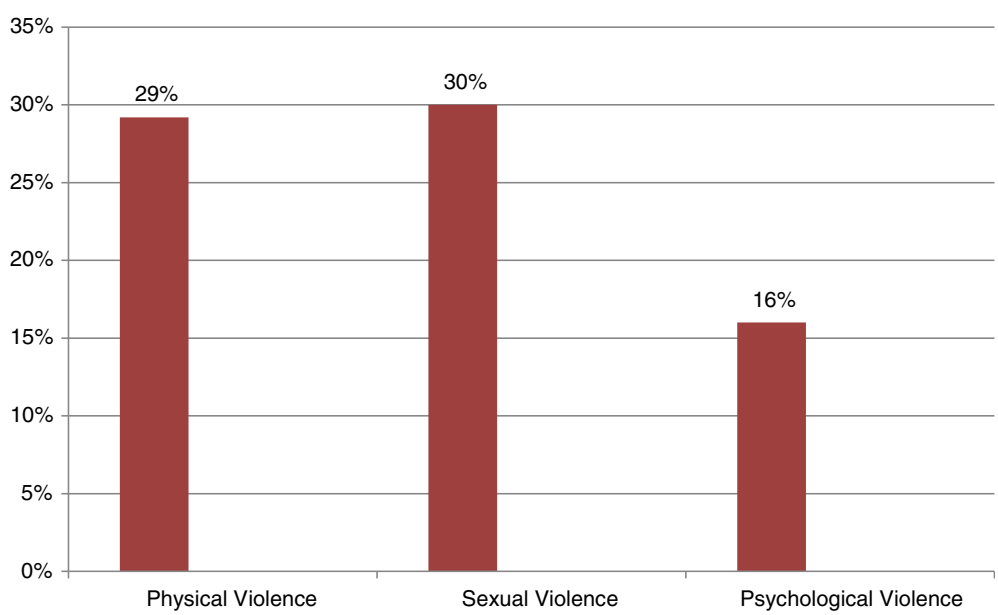

Fig. 1 Forms of intimate partner violence during pregnancy, Abay Chomen district, Western Ethiopia, April 2014

\section{Physical violence}

The prevalence of intimate partner physical violence during recent pregnancy (IPVDP) was $29.2 \%$. The commonly reported type of physical violence was batter 34 (41 \%) followed by hit with fist/something else that could hurt them 18 (21.7) and $25(8.8 \%)$ had reported scar or wound (Table 4). The abdominal beat during recent pregnancy was 38 (13.4), and $72(25.4 \%)$ were beaten before pregnancy.

\section{Sexual violence}

The prevalence of intimate partner sexual violence during recent pregnancy was 85 (30.2\%). About 56 (19.9\%) of the respondents reported that their partners had forced them to have sexual intercourse without their interest or consent during recent pregnancy. In addition, 84 (29.9\%) of respondents experienced sexual intercourse during their pregnancy due to fear of their partners.

\section{Psychological (Emotional) violence}

The prevalence of psychological/emotional intimate partner violence during recent pregnancy was 46 (16.3\%).

Table 4 Types of physical violence's during pregnancy among currently married women aged 15-49, Abay Chomen District, Western Ethiopia, April $2014(n=282)$

\begin{tabular}{ll}
\hline Type of physical violence & Count (\%) \\
\hline Battered & $34(41 \%)$ \\
Pushed or shoved & $6(7.2 \%)$ \\
Slapped or threw something at them & $15(18.1 \%)$ \\
Hit with fist/something else that could hurt her & $18(21.7 \%)$ \\
Kicked, drugged or beat her & $5(6.0 \%)$ \\
Strangled, choked or burnt her on the purpose & $3(3.6 \%)$ \\
Threatened to use knife or gun & $2(2.4 \%)$ \\
\hline
\end{tabular}

Nearly four in ten 18 (37.5\%) of the participating women were verbally insulted and made feel bad about themselves at least once during recent pregnancy. The proportion of both pregnant women humiliated in front of other persons and insisted on them knowing where they were all times was 7 (2.5\%). The percentage of pregnant women who reported stress and depression as a result of violence were 24 (8.5) and 13 (4.6\%) respectively (Table 5).

\section{Factors associated with IPVDP}

Result of binary logistic regression showed that childhood growth areas, partner's education, partner's age, age of marriage, age at first sex, ever lived with partner's family, type of marriage ceremony, dowry payment, dowry impact in future life, having discussant to talk their problem, battering seen during childhood, support of pregnant women battering, money provision and marriage level were identified as significant predictors of experiences of IPVDP (intimate partner violence during recent pregnancy) while respondents' educational status and occupation were not associated.

In multivariable logistic regression three variables i.e. dowry payment impact, partner education and undergoing marriage ceremony were associated. When compared with literates, illiterate partners were $50 \%$ less likely to use violence against their intimate partner during recent pregnancy (AOR 0.5, 95 \% CI 0.2, 0.9).

Pregnant women who reported that dowry payment has positive impact on how they are treated by their husband and his family were 8.7 times more likely to experience IPVDP than those who reported no positive impact on how they are treated by their husband and his family (AOR 8.7, 95 \% CI 4.2, 17.9). Pregnant women who didn't undergo marriage ceremony during their marriage were 4.1 times more likely to experience IPVDP (AOR 4.1, $95 \%$ CI 2, 8.2) (Table 6). 
Table 5 Different types of psychological violence's among currently married women aged 15-49" Abay Chomen District, Western Ethiopia, April $2014(n=282)$

\begin{tabular}{ll}
\hline Type of Psychological violence & Number (\%) \\
\hline Insists on knowing where she go all the time & $18(37.5 \%)$ \\
Belittled or humiliated in front of others & $7(14.6 \%)$ \\
Tried to prevent her from seeing family or friends & $7(14.6 \%)$ \\
Tried to prevent her from seeing other men & $5(10.4 \%)$ \\
Scared or intimidated her on purpose & $5(10.4 \%)$ \\
Blaming for all things & $3(6.2 \%)$ \\
Suspicious for that she were unfaithful & $1(2.1 \%)$ \\
Threatened to hurt her or someone she care about & $2(4.2 \%)$ \\
\hline
\end{tabular}

\section{Discussion}

The study showed that intimate partner violence during recent pregnancy was $44.5 \%$ which was consistent with study from Zimbabwe [23] and higher than studies conducted in USA [24], Japan, and South Africa. This could be because this study included psychological violence as an addition for measuring intimate partner violence during pregnancy $[3,25,26]$ unlike the other studies. The higher prevalence found in this study also might indicate that women were disadvantaged segment of the population and the country's patriarchal society norms.

About three in ten $82(29.2 \%)$ respondents experienced physical violence during recent pregnancy by their intimate partner. It is in agreement with study conducted in Namibia [3] and Tanzania. However, this finding is higher than finding from previous studies in Ethiopia and Serbia and Montenegro [3]. The possible reason might be the presence of traditional norms that support beating pregnant women in the study area because $32(11.4 \%)$ of the respondents reported that they support pregnant women to be battered by her intimate partner.

Likewise, in this study $13.4 \%$ of pregnant women were beaten on their abdomen during pregnancy in which $86.2 \%$ of the assailants were the biological father of the baby they were carrying, which is slightly higher than WHO finding which was $8 \%$ [3]. This can be explained by inter cultural difference among the two study setting as they are south and west Ethiopia settings. Furthermore, it might be due to the fact that WHO study covered a large section of the population where as this study is in one district. The perpetrator, the biological father $(86.2 \%)$

Table 6 Factors associated with intimate partner violence during pregnancy among currently married women aged 15-49, Abay Chomen District, Western Ethiopia, April $2014(n=282)$

\begin{tabular}{|c|c|c|c|c|c|}
\hline \multirow[t]{2}{*}{ Variable } & \multicolumn{5}{|c|}{ Intimate partner violence during pregnancy } \\
\hline & Yes & Yes (\%) & No (\%) & COR $(95 \% \mathrm{Cl})$ & AOR $(95 \% \mathrm{Cl})$ \\
\hline \multirow[t]{2}{*}{ Husband education } & Illiterate & $56(52.8)$ & $50(47.2)$ & $1.7[1,2.8]$ & $0.5[0.2 .0 .9]$ \\
\hline & Literate & $69(39.4)$ & $106(60.6)$ & 1 & 1 \\
\hline \multirow[t]{2}{*}{ Live with husband family } & Yes & $49(35.8)$ & $88(64.2)$ & $0.49[0.3,0.8]$ & $1.7[0.9,3.1]$ \\
\hline & No & $76(52.8)$ & $68(47.2)$ & 1 & 1 \\
\hline \multirow[t]{2}{*}{ Dowry impact } & Positive & $68(33.2)$ & $137(66.8)$ & $0.17[0.09,0.3]$ & $8.7[4.2 .17 .9]$ \\
\hline & Not positive & $125(44.3)$ & $20(26)$ & 1 & \\
\hline \multirow[t]{2}{*}{ To whom they talk violence } & Yes & $102(42.3)$ & $139(57.7)$ & $0.5[0.2,1]$ & $0[0, \infty]$ \\
\hline & No & $23(59)$ & $16(41)$ & 1 & 1 \\
\hline \multirow[t]{2}{*}{ Batter seen during childhood } & Yes & $82(55.4)$ & $66(44.6)$ & $2.6[1.5,4.2]$ & $1.6[0.93,3.1]$ \\
\hline & No & $43(32.3)$ & $90(67.7)$ & 1 & 1 \\
\hline \multirow[t]{2}{*}{ Pregnant women supporting batter during pregnancy } & Yes & $21(65.6)$ & $11(34.4)$ & $2.6[1.2,5.77]$ & $0.4[0.16 .1]$ \\
\hline & No & $103(41.7)$ & $144(58.3)$ & 1 & 1 \\
\hline \multirow[t]{2}{*}{ Money provision of partner } & Yes & $115(46)$ & $135(54)$ & $0.53[0.24,1.1]$ & $1.9[0.77,4.7]$ \\
\hline & No & $10(32.3)$ & $21(67.7)$ & 1 & 1 \\
\hline \multirow[t]{2}{*}{ Marriage frequency } & First & $108(43)$ & $143(57)$ & $0.57[0.26,1.2]$ & $1.1[0.45,2.9]$ \\
\hline & Other & $17(56.7)$ & $13(43.3)$ & 1 & 1 \\
\hline \multirow[t]{2}{*}{ Marriage Ceremony } & No & $28(29.5)$ & $67(70.5)$ & $0.38[0.22,0.64]$ & $4.1[2,8.2]$ \\
\hline & Yes & $97(52.2)$ & $89(47.8)$ & & 0 \\
\hline \multirow[t]{4}{*}{ Husband age } & $18-24$ & $8(32)$ & $17(68)$ & $0.29[0.08,0.97]$ & $0.47[0.11,1.9]$ \\
\hline & $25-34$ & $69(43.9)$ & $88(56.1)$ & $0.48[0.18,1.2]$ & $0.46[0.15,1.3]$ \\
\hline & $35-49$ & $35(44.3)$ & $44(55.7)$ & $0.49[0.18,1.3]$ & $0.48[0.15,1.5]$ \\
\hline & $>=50$ & $13(61.9)$ & $8(38.1)$ & 1 & 1 \\
\hline
\end{tabular}


of the baby she was carrying was lower than previous Ethiopian study [3]. This might be due to presence of polygamy in the study area because 37 (13.1\%) of respondents married to partners who had other wife.

One in three, 85 (30\%) of pregnant women had sexual violence during recent pregnancy. This is similar with study conducted in Tanzania [27] which might be due to shared similar socio economic status. It is higher than findings from Namibia [3]. This might be due to sexual autonomy imbalance among the two study areas.

Overall, the prevalence of psychological intimate partner violence during recent pregnancy was $46(16.3 \%)$ which is lower than study conducted in South Africa which was $49 \%$ [28]. This could be due to difference in the perception of violence in the respective communities [29].

Women who ever lived with their intimate partner's family were $45 \%$ less likely to experience intimate partner violence during pregnancy when compared with women who had not ever lived with their partner's family. This might be explained if pregnant women were attached to their husband's family, their partner's respect might increase and so lower violence.

Unlike other studies, compared with literates, illiterate partners were $50 \%$ less likely to experience violence by their intimate partner during pregnancy. Pregnant women who reported that dowry payment has positive impact in the rest of their lives were 8.7 times more likely to experience IPVDP than those who reported no positive impact. Pregnant women who didn't undergo marriage ceremony during their marriage were 4.1 times more likely to experience IPVDP.

Dowry impact on how they are treated by their husband and his family was also a risk factor for IPVDP as dowry is the payment to be made to the groom's family to marry a daughter, and it takes different forms in different cultures. However, the size of the dowry is a common reason for disputes between the families, with the groom's family demanding more than the bride's family can offer, resulting in violence of brides even to death in India and southern Asian countries [30].

\section{Conclusions}

Intimate partner violence during recent pregnancy is observed in nearly half of the pregnant women in the study area. One in three pregnant women experienced both physical and sexual violence. More than one in ten experienced intimate partner psychological/emotional violence. The implication of the study findings regarding the practice of intimate partner violence during recent pregnancy is common in the study site. To that end, increasing community awareness about the consequences and its adverse reproductive health outcomes of the practice could be an important. Moreover, the health extension workers should be engaged in education, screening and referral of IPVDP victims as they are near to the community. In addition the district education office, office of women's affair should strengthen education on prevention of intimate partner violence in schools. The unique finding from this study is about the association between education and intimate partner violence among pregnant women where it associated positively with less education. To make the associations of demographic variables more clear, we recommend further longitudinal studies to further strengthen the magnitude and associated factors and its effect on pregnant women and the fetus locally.

Moreover, the longitudinal study will help in checking the repeatability of the findings in different areas and with different study design possible to scale it up to incorporate in the government policy.

Competing interests

We, the authors declare that we didn't have competing interests.

\section{Authors' contributions}

BA; Contributed in inception, design, analysis, interpretation, drafting of research manuscript and final approval of the revised manuscript for publication. BA; Contributed in inception, design, analysis, interpretation, drafting the research manuscript and final approval of the revised manuscript for publication. TT; Contributed in inception, design, analysis, interpretation, drafting of research manuscript and final approval of the revised manuscript for publication.

\section{Acknowledgements}

We express our heartfelt thanks to participants for their willingness to participate in the study, without whom this research would be impossible.

\section{Author details}

${ }^{1}$ Department of Social and Public Health, College of Health Sciences, Debre Tabor University, Debre Tabor, Ethiopia. ${ }^{2}$ Department of Population and Family Health, College of Health Sciences, Jimma University, Jimma, Ethiopia. ${ }^{3}$ Institute of Development and Policy Research, Population and Gender Unit, Addis Ababa University, Addis Ababa, Ethiopia.

Received: 18 May 2015 Accepted: 5 March 2016

Published online: 10 March 2016

\section{References}

1. UN General Assembly. Declaration on the elimination of Violence against Women: Resolution A/RES/48/104, 23 February 1994.

2. WHO .Global and regional estimate of violence against women: prevalence and health effects of intimate partner violence and non-partner sexual violence, 2013.

3. García-Moreno C, Jansen HA, Ellsberg M, et al. WHO Multi-Country Study on Women's Health and Domestic Violence against Women: initial results on prevalence, health outcomes and women's responses. Geneva: World Health Organization; 2005.

4. Devries KM, Kishor S, Johnson H, Stöckl H, Bacchus L, Garcia-Moreno C, et al. Intimate partner violence during pregnancy: prevalence data from 19 countries. Reprod Health Matters. 2010;18(36):1-13.

5. Nasir K, Adnan A. Hyde: violence against pregnant women in developing countries. Eur J Public Health. 2003;13:105-7.

6. Ethiopian Journal of Health Development on Butajira Rural Health Program: Women's Health and Life Events Study in Rural Ethiopia Volume 17, Second Special issue 2003 ISSN 1021-679.

7. Deribew A. Magnitude and risk factors of intimate partner violence against women in Agaro town, south west Ethiopia. Ethiop J Health Sci. 2007;17:2.

8. Yigzaw T, Yibrie A, Kebede Y. Domestic violence around Gondar in North west Ethiopia. Ethiop J Health Dev. 2004;189(3):133-9.

9. Dibaba Y. Prevalence and correlates of Intimate partner physical violence against women in Kofale district, Ethiopia. Trop Doct. 2008;389(1):52-4. 
10. Sileshi Garoma A, Mesganaw Fantahun A, Alemayeh Worku Y. Intimate partner violence against women in west Ethiopia: Prevalence, patterns and associated factors. BMC Public Health. 2011;11:913.

11. World Health Organization. World Report on Violence and Health. Geneva: WHO; 2002.

12. Campbell JC. Health consequences of intimate partner violence. Lancet. 2002;359:13311336.

13. Alice H. Maternal and fetal outcomes of intimate partner violence associated with pregnancy in the Latin American and Caribbean region. 2012.

14. Partner Violence during Pregnancy Increases Risk of Adverse Outcomes: Perspectives on sexual and reproductive Health; Guttmacher institute: Volume 35, Number 5, September /October 2003.

15. Taft AJ, Watson LF. Termination of pregnancy: associations with partner violence and other factors in a national cohort of young Australian women. Aust N Z J Public Health. 2007:31(2):135-42.

16. Rodrigues $T$, Rocha L, Barros H. Physical abuse during pregnancyand preterm delivery. Am J Obstet Gynecol. 2008;198(2):171. e1-e6.

17. Martin SL, Li Y, Casanueva C, Harris-Britt A, et al. Intimate partner violence and women's depression before and during pregnancy. Violence Against Women. 2006;12(3):221-39.

18. Ahmed A. Maternal Mortality Trend in Ethiopia. Obstetrics \& Gynecology Department Addis Ababa University. Ethiop J Health Dev. 2010;24(1):115-122

19. Abay Chomen district health office first quarter report, October 2014.

20. The WHO Multi-Country Study on Women's Health and Domestic Violence: Notes on Use of the Questionnaire. (Version 10), 20 September 2003.

21. Guidelines for HIV Counseling and Testing in Ethiopia. Federal HIV/AIDS Prevention and Control Office Federal Ministry of Health July 2007.

22. World Health Organization. Putting Women's Safety First: Ethical and Safety Recommendations for Research on Domestic Violence Against Women. Geneva: Global Programme on Evidence for Health Policy, World Health Organization; 1999. Report No.: WHO/EIP/GPE/99.2.

23. Watts C, Keough E, Ndlovu M, Kwaramba R. Withholding of sexand forced sex: dimensions of violence against Zimbabwean women. Reprod Health Matters. 1998;6:57-65.

24. Charlesa P, Perreirab KM. Intimate partner violence during pregnancy and 1-year post-partum. 2009.

25. Me H. Mhoquesbkader prevalence and experience of domestic violence among rural pregnant women in kwazulu-natal, south Africa. South Afr J Epidemiol Infect. 2009:24(4):34-7.

26. Janssen PA, Holt VL, Sugg NK, Emanuel I, Critchlow CM, Henderson AD. Intimate Partner Violence and Adverse Pregnancy Outcomes: A PopulationBased Study. Am J Obstet Gynecol. 2003;188:1341-7.

27. Stöckl et al. Induced abortion, pregnancy loss and intimate partner violence in Tanzania: a population based study. BMC Pregnancy Childbirth. 2012;12:12. http://bmcpregnancychildbirth.biomedcentral.com/articles/10.1186/1471-239312-12. Accessed on November 162013

28. Jewkes R, Penn-Kekana L, Levin J, Ratsaka M, Schrieber M. Prevalence of Emotional, Physical and Sexual Abuse of Women in three South African Provinces. S Afr Med J. 2001;91:421-8.

29. Mathews S, Abrahams N, Martin L, Van der Merwe L, Jewkes R. Every six hours a woman is killed by her intimate partner: A national study of female homicide in South Africa. Cape Town: Medical Research Council; 2004

30. Gangrade KD. Social development and the girl child. Soc Change. 1995:25:70-83

\section{Submit your next manuscript to BioMed Central and we will help you at every step:}

- We accept pre-submission inquiries

- Our selector tool helps you to find the most relevant journal

- We provide round the clock customer support

- Convenient online submission

- Thorough peer review

- Inclusion in PubMed and all major indexing services

- Maximum visibility for your research

Submit your manuscript at www.biomedcentral.com/submit 